\title{
Analysis and Maximizing Energy Harvesting from RF Signals using T-Shaped Microstrip Patch Antenna
}

\author{
Muhammad Salman Iqbal ${ }^{1,}$, , Tariq Jameel Khanzada, ${ }^{2, \#}$, Faisal A. Dahri ${ }^{3,}$, Asif Ali ${ }^{4,}{ }^{*}$, Mukhtiar Ali ${ }^{5,}$, Abdul Wahab \\ Khokhar ${ }^{6, \$}$ \\ IICT, MUET, Jamshoro, Pakistan* \\ CSE Department MUET, Jamshoro, Pakistan \# \\ IICT, Univeristy of Sindh, Pakistan $\$$
}

\begin{abstract}
The advancement of the modern world requires catering the power crisis. New methodologies for energy harvesting were considered, but their succession in a different environment is still to explore. This paper deals with antenna designing to harvest energy from radio signals. The rummage of energy from surrounding sources is considered a harvesting of energy and it would be an alternative approach for low energy utilization. As comparatively well-known sources are considered for energy harvesting; such as wind and solar, radio frequency signal can provide continues supply of energy harvesting. Alternatively, we are getting the maximum usable energy resources which are challenging the amplitude of arriving signal, which is considered very low and the requirements for operating available antennas are proportionally higher. Using the Microstrip patch antenna limited the energy resources, because it is low profile, easy to configure, simple in design at the lowest rate. Furthermore, the combined the configuration and proposed antenna design provide the maximum energy efficiency. More simulation iterations are performed to maximize the gain of ISM band of $2.4 \mathrm{GHz}$. The operating frequency of microstrip patch antenna is $2.4 \mathrm{GHz}$, which provides the gain of $7.2 \mathrm{~dB}$, return loss $-20 \mathrm{~dB}$ and the directivity of $7.44 \mathrm{~dB}$. The achieved result of source voltage is $900 \mathrm{mv}$ after rectification the output voltage $2.5 \mathrm{v}$. The results are efficient and suitable to overcome litter bit power crisis.
\end{abstract}

Keywords-Microstrip patch antenna; radio frequency; energy harvesting; ISM band; gain; return loss and directivity

\section{INTRODUCTION}

The energy harvesting is the method through the energy is derived from the external sources like: solar power, thermal energy, kinetic energy and wind energy. The energy harvester supplies low energy for low power consumption devices. While some of the existing resources of energy sources give an opportunity to the harvesters nearby as ambient background. Currently, the fast growth of wireless operated systems and researchers are engaged to get more energy from energy harvesting technology to off the load from electricity suppliers [1]. Ambient radio frequency energy is enveloping, particularly for Wi-Fi and mobile networks. The energy harvesting is possibly taken from the mobile phones and it would be used for low power devices and short range applications [2]. The idea of energy harvesting is not innovative rather than it came hundred years ago. The method of energy harvesting is to extract the energy from the environment to produce the electricity is known as the energy harvesting or energy scavenges [3]. This technology mainly offers the freely available energy and the green environment. The energy harvesting is available around us can be harvested to rectifying antenna generally known as rectenna. The rectenna is the process of rectifying antenna which is used to convert the electromagnetic energy into electrical energy [4]. The rectenna refers to the high frequency signal can be harvested from the free space and converted into the DC power as well. The energy harvesting from the RF can be useful in terms of DC power which is designed in the below Fig. 1 demonstrated the Antenna signal amplification and matching circuit for the maximum power transfer from the RF signal.

In last few decades, the usage of wireless communication systems and its applications are increasing the day by day, which is rapid growth in the incensement of battery usage. The batteries are used in this application very rear such as periodical replacement of batteries is required in order to the application. Sometimes it is very difficult to change the manually charged system [5]. Recently, the interest in radio frequency (RF) energy harvesting/scavenging has been increased due to its advantages and RF harvesting having potential of converting radio received signal into electrical signals [6]. Energy harvesting is the process of scavenging ambient energy from sources in the surrounding environment.

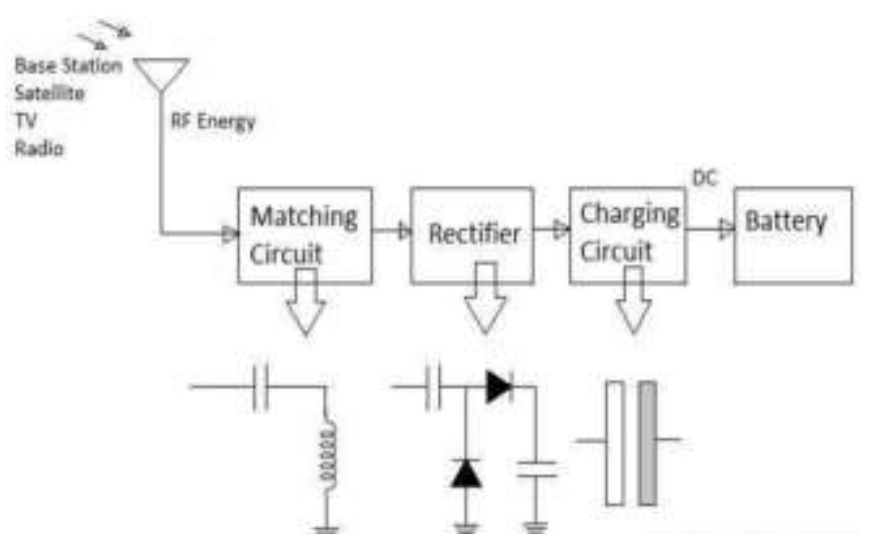

Fig. 1. RF Energy Harvesting Block Diagram. 


\section{LITERATURE STUDY}

The previous study on energy harvesting is summarized as the following. The performance of a wireless system is restricted through the fundamental energy. To study energy harvesting based on wireless communication channel and its interference status of the point to point link [7], [8]. The author discussed ultra-low power chip based system which harvest energy form sensing applications. Three chip system contains emulation resistor circuit and radio frequency DC rectifier [9]. The some assumption are taken for wireless systems in response of energy harvesting those having a constant conversion of energy from energy harvesters [10], also energy harvesting technology is under deployment phase to facilitate low power devices in wireless networks [11]. To analyze energy harvesting based cognitive radio system. During the sensing of primary user and transmission time, energy is harvested from cognitive radio [12]. The integration of harvesting and multiple antennas would be a viable solution for enhancing energy efficiency and decreasing transmission power as a requirement of the system. [13], [14]. The multirelay system is considered and studied that how much each relay divide received RF signal power to maximization of data transfer [15]. Important parameter of the antenna utilized in energy yielding is their radiation efficiency which is identified with the its losses include dielectric and conducting along with the effectiveness, which in addition considers the accounting of mismatch losses between antenna and its feeding methods. An efficient dual band antenna for boosting reception of ambient RF signals with wide bandwidth in Wi-Fi bands $2.45 \mathrm{GHz}$ and $5 \mathrm{GHz}$ has been investigated in [16] which provide an alternative source to power sensors in harsh environments and remote places.

\section{Simulated Proposed AnTEnNa Design}

The simulation tool is used for antenna designing is the High frequency structure simulator (HFSS). The simple microstrip patch antenna is designed using the substrate material duroid roger 5880. It has the dielectric constant value is 2.5 and the loss tangent is 0.0008 , which is given in the below Table 1 and we have to calculate the width (Wp) and length (Lp) of the patch antenna through the following equation (1) and (2) [17], which is approximate the $40 \mathrm{~mm}$ and $43 \mathrm{~mm}$ respectively shown in the given Fig. 3.

$$
\begin{aligned}
& W=\frac{\lambda_{o}}{2}\left(\frac{2}{\epsilon_{r}+1}\right)^{\frac{1}{2}} \\
& L=\frac{1}{2 f_{r} \sqrt{\epsilon_{e f f}} \sqrt{\mu_{o}} \epsilon_{o}}-2 \Delta L
\end{aligned}
$$

In above equations the $\mathrm{c}$ is the speed of light, $\in_{\text {reff }}, \mu_{o}$ and $\Delta L$ are the effective dielectric constant, second is permeability of the free space and the extension length is denoted by $\Delta L$ and the effective dielectric constant $\in_{\text {reff }}$ can be computed through following equations, respectively as.

$$
\begin{aligned}
& \Delta L=0.412 h\left[\left(\frac{\epsilon_{\text {reff }}+0.3}{\epsilon_{\text {reff }}-0.258}\right)\left(\frac{\frac{W}{h}+0.264}{\frac{W}{h}+0.813}\right)\right] \\
& \in_{\text {eff }}=\frac{\epsilon_{r}+1}{2}+\frac{\epsilon_{r}-1}{2}\left[\left(1+\frac{12 W}{h}\right)\right]^{\frac{-1}{2}}
\end{aligned}
$$

The radiating patch size is represented as $L p * W p$. While the substrate width and length is highlighted as Ws and Ls. The operating frequency of designing antenna, the dielectric constant and the height of the substrate are $2.4 \mathrm{GHz}, 4.3$ and $1.5 \mathrm{~mm}$, respectively. As the design model considered as a proposed antenna model which is analyzed as transmission line, therefore the $\mathrm{Wp}$ and $\mathrm{Lp}$ can be calculated through the given formulas as suggested in [18-20]. The proposed antenna design for the microstrip patch antenna is suggested the inset fed for the input impedance Zo as $50 \Omega$.

The antenna is simulated in the HFSS simulator; thus, the specific values are required to design the antenna in estimated simulator. The simulation parameter values are calculated from the specified equations as mentioned in the section. After numerical calculations, the proposed antenna is modeled as the sample of patch antenna is shown in Fig. 2.

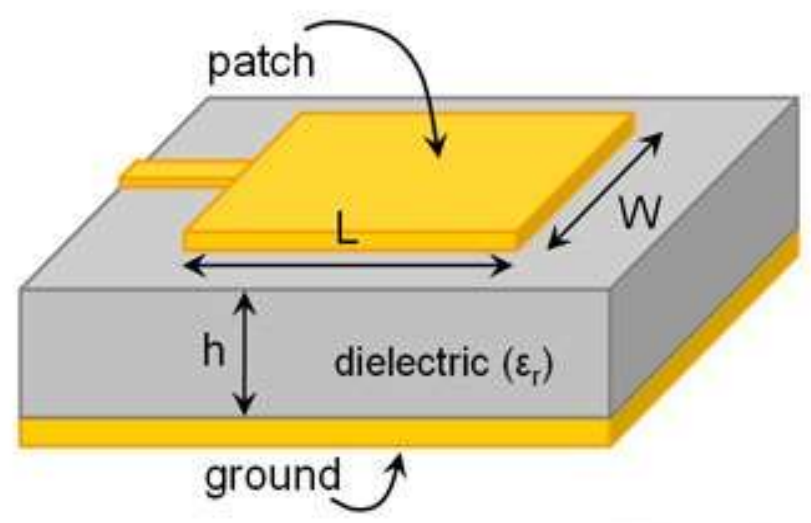

Fig. 2. Basic Microstrip Patch Antenna Design.

TABLE I. SiMULATION DESIGN SPECIFICATIONS OF ENERGY HARVESTING ANTENNA

\begin{tabular}{|c|l|l|}
\hline S. no. & Parameters & \multicolumn{1}{|c|}{ Values } \\
\hline 1. & $\begin{array}{c}\text { Substrate Dielectric } \\
\text { Constant }\end{array}$ & 4.3 \\
2. & Inset Gap & $4 \mathrm{~mm}$ \\
3. & Inset Length & $8 \mathrm{~mm}$ \\
4. & Substrate Thickness & $1.5 \mathrm{~mm}$ \\
5. & Operating Frequency & $2.4 \mathrm{GHz}$ \\
6. & Patch Width & $40 \mathrm{~mm}$ \\
7. & Patch Length & $43 \mathrm{~mm}$ \\
8. & Substrate Width & $60 \mathrm{~mm}$ \\
9. & Substrate Length & $60 \mathrm{~mm}$ \\
10. & Feed Width & $7 \mathrm{~mm}$ \\
11. & Feed Length & $16 \mathrm{~mm}$ \\
12. & Input Impedance & $50 \Omega$ \\
\hline
\end{tabular}




\section{Simulation ReSUlts AND DiscUSSION}

In this section, we discussed about the simulation parameters and their results. The T-shaped microstrip patch antenna is simulated and configuration of the proposed antenna in HFSS simulator demonstrated in Fig. 3. The Tshaped antenna having a slot on the patch looking like $\mathrm{T}$ alphabet and it is used to get more energy for the energy harvesting system as results reveals in subsequent section.

The antenna simulation parameters are already discussed in the previous session. The simulation results are presents in the given section.

The antenna rectifier model is developed as shown in Fig. 4. The RF input signal is used in simulation is presented in Fig. 5. By the trial and error method, the achieved results were determined as more than $900 \mathrm{mv}$. The rectified and filtered output of the simulated circuit design is depicted in Fig. 6. The variation of the simulated return loss as a function of frequency is presented microstrip patch antenna which is presented in Fig. 7. The air gap is varied; the bandwidth and gain do not show significant changes. However, the return loss is increased as the air gap increases.

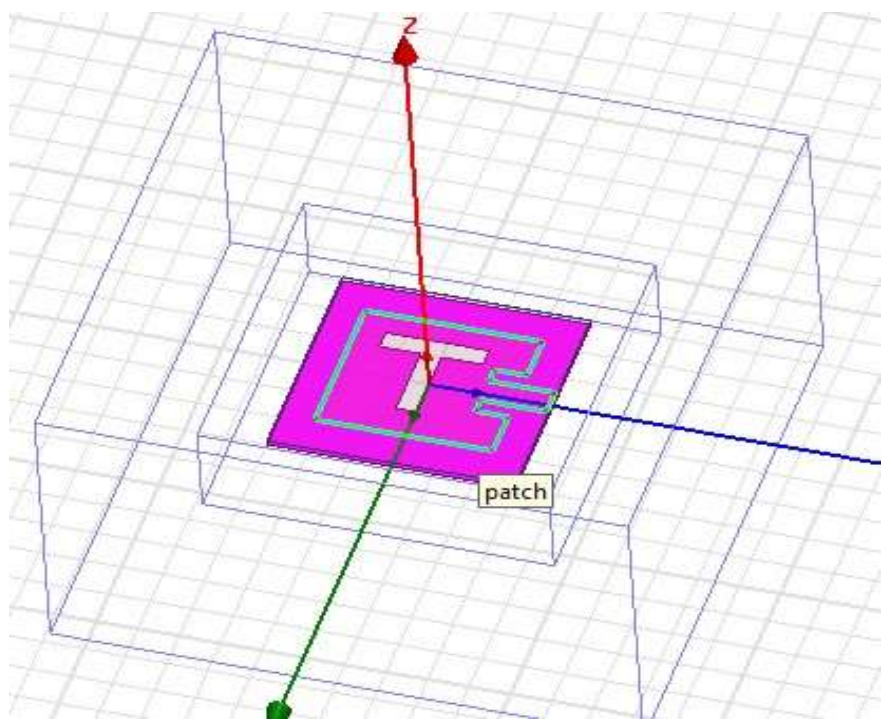

Fig. 3. T-Shaped Microstrip Patch Antenna in HFSS Simulator.

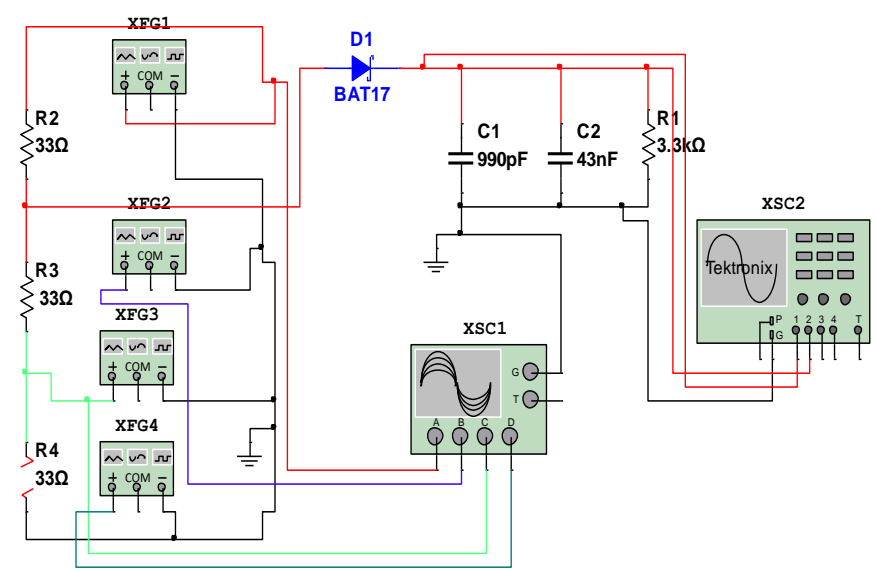

Fig. 4. Circuit Diagram of Rectifier for RF Harvesting in Multisim V14.

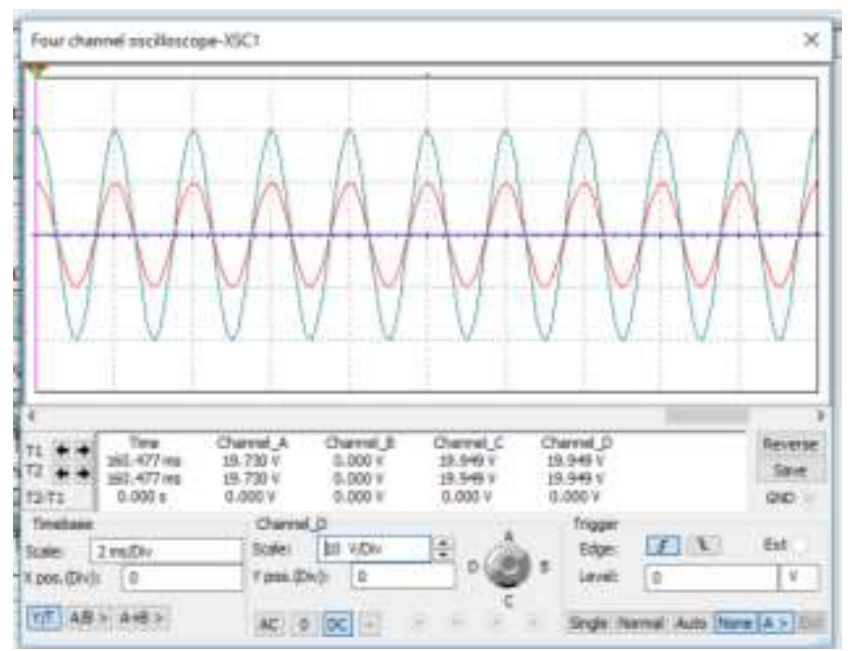

Fig. 5. RF Input Signal to the Rectifier Circuit.

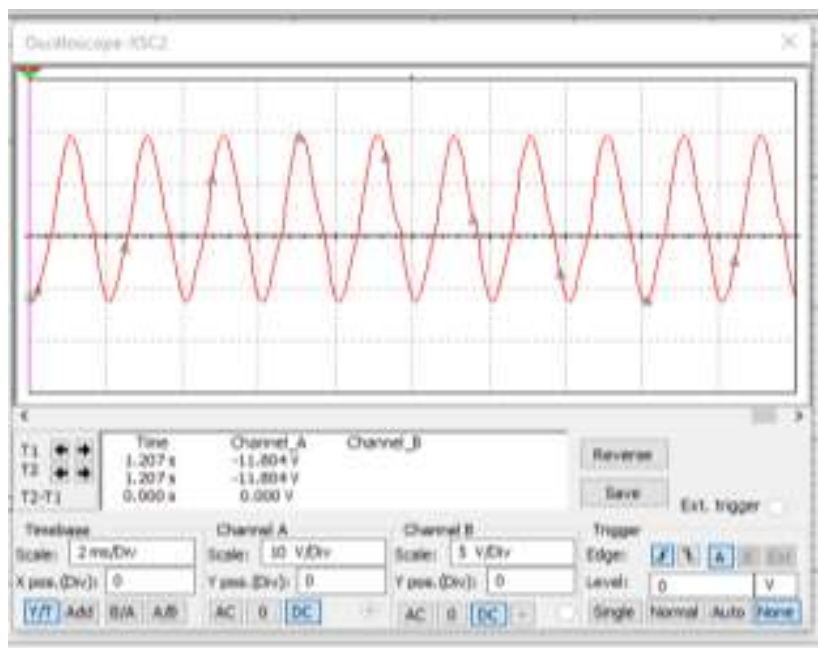

Fig. 6. Filtered and Rectified Output of Simulated Circuit.

Antenna size and frequency are related inversely so operating range of $2.4 \mathrm{GHz}$ will result in miniaturized design and its given frequency they obtained return loss is $-20 \mathrm{~dB}$. The term gain expresses the radio waves are directed in a direction which is the converted form of input power. In the Fig. 8 illustrates the maximum gain $7.2 \mathrm{~dB}$ is achieved at frequency of $2.4 \mathrm{GHz}$. The omnidirectional directivity is experienced and having a numeric value of $7.44 \mathrm{~dB}$ as shown in Fig. 9. The acquired simulation results are suitable for the energy harvesting applications. The 3D polarization results have also been measured to confirm the good polarization. The following Fig. 10 shows the polarization around 6.071 magnitudes. The polarization is mostly directed in horizontal direction is suitable for $\mathrm{EH}$ application. Fig. 11 illustrates the result of T-shaped microstrip patch antenna of the Radiation pattern of gain, it is good radiation pattern that covers the front direction, it also describes the vertical half power-beam width. The voltage standing wave ratio (VSWR) of the T-shaped microstrip patch antenna is measured as a 1.2 and the input impedance of the simulated antenna is 49.5 which is nearly equal to the value of set impedance or input impedance, which demonstrate that the suggested antenna has minimum losses. 


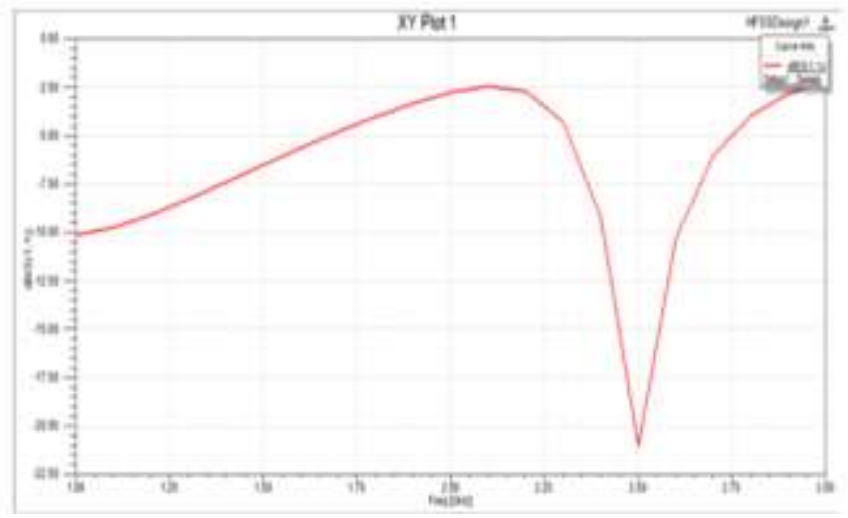

Fig. 7. T-Shaped Microstrip Patch Antenna Simulated Return Loss.
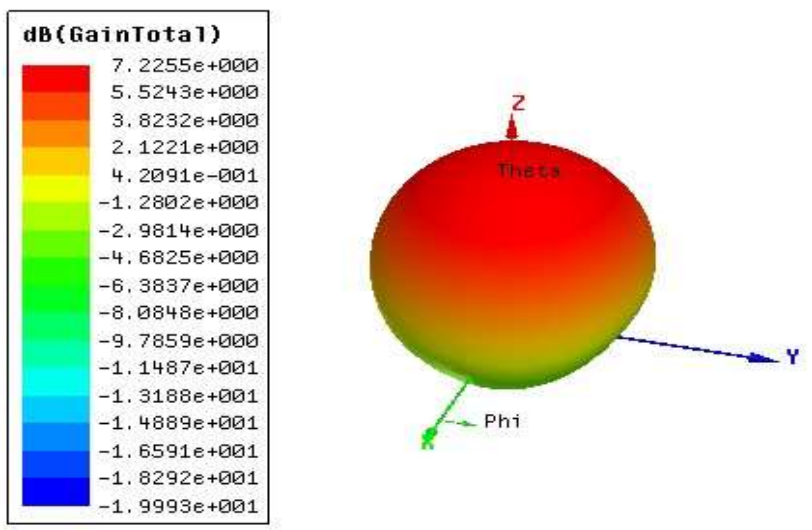

Fig. 8. T-Shaped Microstrip Patch Antenna Simulated 3D Gain.

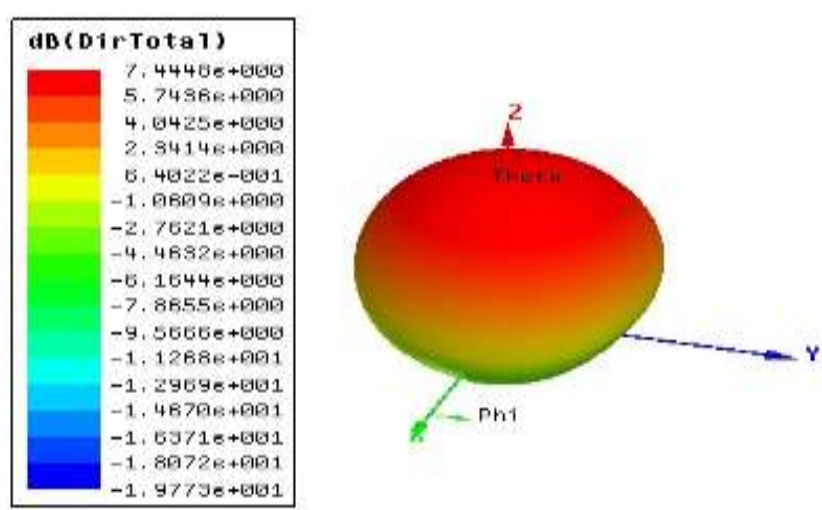

Fig. 9. T-Shaped Microstrip Patch Antenna Simulated Directivity.

The performance of $U$ and $T$-shaped antenna is quite similar but in u shape having more harmonics are experienced. The T-shape performs better in a freely available spectrum, which is considered a wireless local area network. The efficiency of antenna is quite good in gain and directivity to capture the RF signals from the free space. The authors [21] have achieved a low gain so that $\mathrm{T}$-shape antenna is preferable over U-shaped antenna.

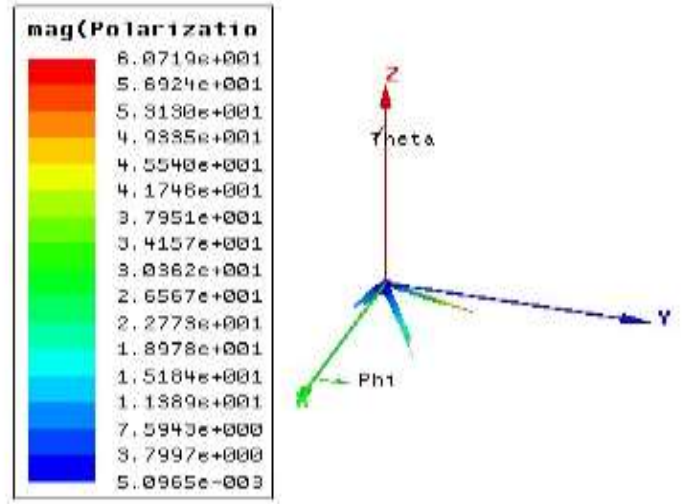

Fig. 10. T-Shaped Microstrip Patch Antenna Simulated Polarization.

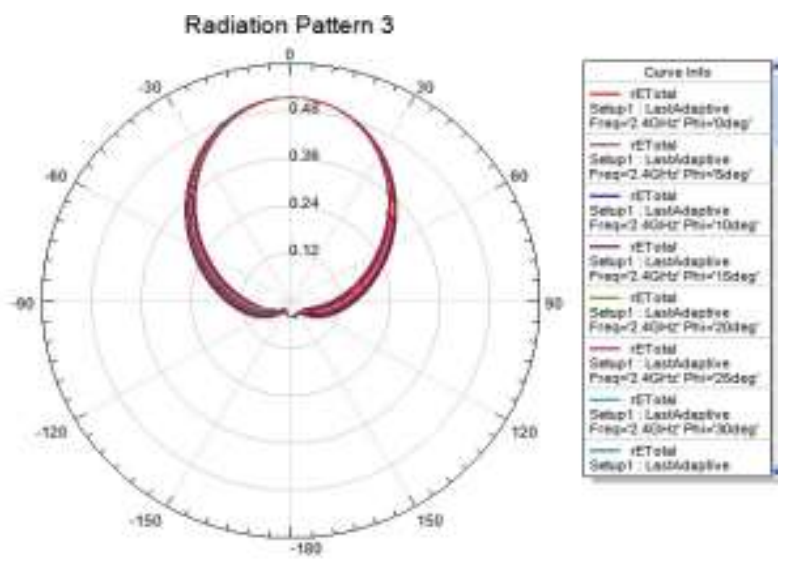

Fig. 11. T-Shaped Microstrip Patch Antenna Simulated Radiation Pattern.

\section{CONCLUSION}

T-shaped microstrip patch antenna is designed for energy harvesting in one of the well-known simulator high frequency structure simulator (HFSS) software. The size of antenna is 60x60mm using FR4 substrate material with dielectric constant of 4.3 along the operating frequency $2.4 \mathrm{GHz}$. The feature of proposed antenna is studied and has been optimized to get better results using a simulation platform. Numbers of simulation iterations were performed to check the performance of antenna in order to maximize gain around the ISM band of $2.4 \mathrm{GHz}$. Energy radiation distributions in space are presented through a quasi-omnidirectional radiation pattern at the frequency of $2.4 \mathrm{GHz}$. Low power consuming electronic devices and sensor networks are main target of energy harvesting to get more benefits from these networks. The presented work has more potential for future networks which will be only a way to power the network through harvesting technology. The result shows that it can work properly with low return loss, relatively high gain and good radiation pattern. The expected characteristics are obtained, and hence the proposed antenna is substantial and to be used as the front-end section of an energy harvesting system. The return loss of $-20 \mathrm{~dB}$ is noted at resonating frequency of 2.4 $\mathrm{GHz}$ with gain is $7.2 \mathrm{~dB}$ and directivity of $7.44 \mathrm{~dB}$. This antenna is suitable candidate for the energy harvesting applications. Rectifier simulation results are validated and 
indicated that how RF vitality has been achieved, signal is amplified and after harvesting performed using well known software named as Multisim. The achieved results present the suitability of rectifier circuit.

\section{REFERENCES}

[1] X. Bao, K. Yang, O. O. Conchubhair, and M. J. Ammann, "Differentially-fed Omnidirectional Circularly Polarized Patch Antenna for RF Energy Harvesting," Antenna High Freq. Res. Cent., 2017.

[2] M. Piñuela, S. Member, P. D. Mitcheson, and S. Member, “Ambient RF Energy Harvesting in Urban and Semi-Urban Environments," vol. 61, no. 7, pp. 2715-2726, 2013.

[3] S. Patil, "Design and Implementation of Microstrip Antenna for RF Energy Harvesting," vol. 10, no. 1, pp. 487-490, 2017.

[4] M. Arrawatia, M. S. Baghini, and G. Kumar, "Broadband RF Energy Harvesting System covering CDMA, GSM900, GSM1800 , 3G Bands with Inherent Impedance Matching,” pp. 30-32, 2016.

[5] D. Bouchouicha, F. Dupont, M. Latrach, and L. Ventura, "Ambient RF Energy Harvesting,” (ICREPQ'10), vol. 1, no. 8, pp. 1309-1313, 2010.

[6] Y. Bhole, S. Chaugule, B. Damankar, and V. Yadav, "ENERGY HARVESTING FROM RF SIGNAL,” Int. J. Adv. Res. Comput. Eng. Technol., vol. 4, no. 3, pp. 985-989, 2015.

[7] L. Liu, R. Zhang, and K. Chua, "Wireless Information Transfer with Opportunistic Energy Harvesting,” vol. 12, no. 1, pp. 288-300, 2013.

[8] T. Wu, H. Yang, and S. Member, "On the Performance of Overlaid Wireless Sensor Transmission With RF Energy Harvesting," vol. 33, no. 8, pp. 1693-1705, 2015.

[9] Y. Chen, S. Member, K. T. Sabnis, R. A. Abd-alhameed, and B. H. I. Power, "New Formula for Conversion Efficiency of RF EH and Its Wireless Applications," vol. 65, no. 11, pp. 9410-9414, 2016.

[10] K. H. Li and S. Member, "Channel Selection in Multichannel Cognitive Radio Systems Employing RF Energy Harvesting,” vol. 65, no. 1, pp. 457-462, 2016.

[11] D. Altinel, G. K. Kurt, and S. Member, "Energy Harvesting From Multiple RF Sources in Wireless Fading Channels," vol. 65, no. 11, pp. 8854-8864, 2016.
[12] N. Jose, N. John, P. Jain, P. Raja, and T. V Prabhakar, "RF Powered Integrated System for IoT Applications.".

[13] Z. Zhou, S. Zhou, J. Gong, and Z. Niu, "Energy-E ffi cient Antenna Selection and Power Allocation for Large-Scale Multiple Antenna Systems with Hybrid Energy Supply,” no. 61201191, pp. 2574-2579, 2014.

[14] G. Yang, C. K. Ho, and Y. L. Guan, "Multi-antenna Wireless Energy Transfer for Backscatter Communication Systems," vol. 33, no. 12, pp. 2974-2987, 2015.

[15] C. Zhang and L. Hu, "Iterative Dynamic Power Splitting for Multi-relay Networks with Wireless Energy Harvesting," IEEE Signal Process., vol. 22, no. 12, pp. 2274-2278, 2015.

[16] M. Z. A. A. Aziz and M. N. Husain, "Dual-Band Monopole Antenna For Energy Harvesting System," ieee Symp., pp. 225-229, 2013.

[17] N. Girase, "Design and Simulation of Slotted Rectangular Microstrip Patch Antenna Design and Simulation of Slotted Rectangular Microstrip Patch Antenna," Int. J. Comput. Appl. (0975 - 8887), vol. 103, no. October 2014, pp. 19-23, 2017.

[18] A. Ali and M. M. Jawaid, "Design and Simulation of a Rectangular EShaped Microstrip Patch Antenna for RFID based Intelligent Transportation,” Int. J. Adv. Comput. Sci. Appl., vol. 9, no. 4, pp. 165$169,2018$.

[19] Faisal Ahmed Dahri, Riaz A. Soomro, Sajjad Ali Memon, Zeeshan Memon and Majid Hussain Memon, "An Optimized Inset Feed Circular Cross Strip Antenna Design for C-Band Satellite Links" Int. J. Adv. Comput. Sci. Appl., vol. 9 (IJACSA),9(5), 2018.

[20] Dahri, Faisal Ahmed, Riaz A. Soomro, and Zeeshan Ali Memon. "Design of Wearable Microstrip Yagi Array Antenna aimed for Telemedicine Applications." Academic Journal of Management Science (AJMS) 5, no. 2 (2017): 45-52.

[21] S. Parasuraman and G.P.R. Ramesh, 2017." Efficient Design of U-Shape Microstrip Patch Antenna for RF Energy Harvester Application". Journal of Engineering and Applied Sciences, 12: 6699-6702. 